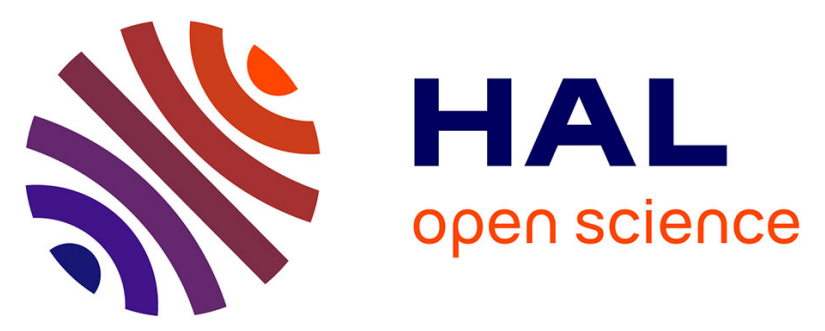

\title{
Biogeochemical regions of the Mediterranean Sea: an objective multidimensional and multivariate environmental approach
}

\author{
Gabriel Reygondeau, Cécile Guieu, Fabio Benedetti, Jean-Olivier Irisson, \\ Sakina-Dorothée Ayata, Stéphane Gasparini, Philippe Koubbi
}

\section{To cite this version:}

Gabriel Reygondeau, Cécile Guieu, Fabio Benedetti, Jean-Olivier Irisson, Sakina-Dorothée Ayata, et al.. Biogeochemical regions of the Mediterranean Sea: an objective multidimensional and multivariate environmental approach. Progress in Oceanography, 2017, 10.1016/j.pocean.2016.11.001. hal-01409074

\section{HAL Id: hal-01409074 \\ https://hal.sorbonne-universite.fr/hal-01409074}

Submitted on 5 Dec 2016

HAL is a multi-disciplinary open access archive for the deposit and dissemination of scientific research documents, whether they are published or not. The documents may come from teaching and research institutions in France or abroad, or from public or private research centers.
L'archive ouverte pluridisciplinaire HAL, est destinée au dépôt et à la diffusion de documents scientifiques de niveau recherche, publiés ou non, émanant des établissements d'enseignement et de recherche français ou étrangers, des laboratoires publics ou privés. 


\section{Biogeochemical regions of the Mediterranean Sea: an objective multidimensional and multivariate environmental approach}

Gabriel Reygondeau $^{1,2,3}$, Cécile Guieu ${ }^{1,2}$, Fabio Benedetti ${ }^{1,2}$, Jean-Olivier Irisson ${ }^{1,2}$, Sakina-Dorothée Ayata ${ }^{1,2}$, Stéphane Gasparini ${ }^{1,2}$, and Philippe Koubbi ${ }^{4}$.

1 Sorbonne Universités, UPMC Univ Paris 06, UMR 7093, LOV, Observatoire Océanographique, F-06230, Villefranche/mer, France

2 CNRS, UMR 7093, LOV, Observatoire Océanographique, F-06230, Villefranche/mer, France

${ }^{3}$ now at : Nippon Foundation-Nereus Program and Changing Ocean Research Unit, Institute for the Oceans and Fisheries, University of British Columbia. Aquatic Ecosystems Research Lab. 2202 Main Mall. Vancouver, BC V6T 1Z4. Canada.

4 Unité Biologie des organismes et écosystèmes aquatiques (BOREA, UMR 7208), Sorbonne Universités, Muséum national d'Histoire naturelle, Université Pierre et Marie Curie, Université de Caen Basse-Normandie, CNRS, IRD; CP26, 57 rue Cuvier 75005 Paris, France.

Revised Article for Progress in Oceanography 


\section{Abstract}

When dividing the ocean, the aim is generally to summarise a complex system into a representative number of units, each representing a specific environment, a biological community or a socio-economical specificity. Recently, several geographical partitions of the global ocean have been proposed using statistical approaches applied to remote sensing or observations gathered during oceanographic cruises. Such geographical frameworks defined at a macroscale appear hardly applicable to characterise the biogeochemical features of semi-enclosed seas that are driven by smaller-scale chemical and physical processes. Following the Longhurst's biogeochemical partitioning of the pelagic realm, this study investigates the environmental divisions of the Mediterranean Sea using a large set of environmental parameters. These parameters were informed in the horizontal and the vertical dimensions to provide a 3D spatial framework for environmental management (12 regions found for the epipelagic, 12 for the mesopelagic, 13 for the bathypelagic and 26 for the seafloor). We show that: (1) the contribution of the longitudinal environmental gradient to the biogeochemical partitions decreases with depth; (2) the partition of the surface layer cannot be extrapolated to other vertical layers as the partition is driven by a different set of environmental variables. This new partitioning of the Mediterranean Sea has strong implications for conservation as it highlights that management must account for the differences in zoning with depth at a regional scale.

Keyword: biogeography, Longhurst approach, 3D partition, ocean, vertical divisions, environmental conditions, semi-enclosed sea. 


\section{Introduction}

In recent decades, several divisions of the global ocean have been proposed. Each division aims at summarising environmental and/or biological global complexity into comprehensive atlases: the Large Marine Ecosystems (LME, Sherman, 2005), the Marine Ecoregions Of the World (MEOW, Spalding et al., 2007) or the BioGeoChemical Provinces (BGCP, Longhurst, 2007). Yet, such macro-ecological partitions are hardly applicable for regional seas since they do not intend to capture the full biogeochemical and physical complexity inherent to such scale (Reygondeau et al., 2013). However, marine ecosystem management policies are developed and implemented at Oceanic basin or semi-enclosed sea scales (e.g., OSPAR, CCAMLR, HELCOM, GFCM, etc.), thereby requiring regionally specific ecosystem information and spatial delineation. In order to provide optimal conservation management, appropriate downscaling approaches must be performed.

The Mediterranean Sea (MS) is a semi-enclosed regional sea surrounded by heavily populated areas of 23 different countries, and where the number of endemic species is considered one of the highest in the world ocean (Cuttelod et al., 2009). Historically, the MS has been divided into 8 zones by the International Hydrographic Organisation: Adriatic Sea, Aegean Sea, Alboran Sea, Levantine Sea, Ionian Sea, Tyrrhenian Sea, Algerian-Provencal basin and Tunisian-Syrian Gulf (see supplementary Fig. 1). However, these divisions relied on the basin's topography and coastline morphology as well as sea governance delineation (e.g. Exclusive Economic Zone). Nevertheless, these partitions have been widely used for the European Marine 
Strategy, for fishing quotas quantification, and for other economic and political management strategies.

Recent ecological studies promoting ecosystems-based management have stressed the need for a more objective division based on environmental/ ecological parameters, in order to provide an accurate representation of the ecological complexity. So far, only coarse partitions of the MS have been proposed in macro-ecological studies: 1 biogeochemical province according to Longhurst (2006) and 6 MEOWs mostly relying on the EEZ (i.e. Exclusive Economic Zone) definition according to Spalding et al. (2007). More recently, some studies have attempted to partition the MS either by using classical abiotic parameters (temperature, salinity or chlorophyll-a; Gabrié et al., 2012), hydrodynamics (Rossi et al., 2014; Berline et al., 2014), satellite-derived estimates of chlorophyll-a seasonality (D'Ortenzio and D'Alcala, 2009), or meso-scale environmental parameters (Nieblas et al., 2014). Such approaches rely solely on surface and a few selected parameters, therefore failing to fully capture the environmental complexity of the MS.

In this study, we aim to identify all the various environmental / pelagic habitat conditions that could be encountered at the scale of the MS. We investigate whether the considerations of a larger number of environmental parameters and the vertical dimension would better capture the full hydrodynamic and biogeochemical complexity of the basin. Following the macroecological approach promoted by Longhurst, we provide a new regional delineation here named biogeochemical regions (BGCR) based on annual mean biogeochemical and hydrodynamic conditions. First, the depth of each vertical boundary of the water column (epipelagic, mesopelagic and bathypelagic) and seafloor is numerically quantified. Second, 
based on a comprehensive annual environmental climatology (16 physical, chemical and biophysical variables), the biogeochemical regions within each pelagic layer and seafloor are characterised by using several multivariate analyses (validated by independent measures for the shallow waters). For each vertical layer, the strength of the boundaries between each BGCR is quantified and the contribution of each environmental parameter to the partitioning is provided. Finally, after a validation process involving recent independent in situ observations, the first 3D biogeochemical partition of the MS is proposed.

\section{Materials and Methods}

\subsection{Environmental data}

To identify the different types of environmental conditions and hence the marine habitats that could be encountered in the MS, the annual climatologies of 16 environmental parameters were gathered. The set of environmental parameters used for this study (Table 1.), was established according to the literature on macroecological partitioning (Longhurst, 2007; Sherman, 2005; Spalding et al., 2008; Reygondeau et al., 2013). It has been gathered to depict and/or characterise specific oceanographic features according to geography (shelf break, river runoff, ...), hydrodynamics (gyral system, frontal structure, coastal upwelling) or Low Nutrient Low Chlorophyll (LNLC) areas. All the information about the dataset are summarised in Table 1.

Most of the environmental parameters were collected from a single source (MEDAR/MEDATLAS datasets; MEDAR Group, 2002): temperature, salinity, nitrates, nitrites, orthophosphates, silicates, $\mathrm{pH}$, chlorophyll-a concentration, and 
dissolved oxygen concentration (see Table 1.). These datasets were obtained from oceanographic campaigns and remote sensing observations. Each environmental variable is spatially resolved over the whole basin at a $0.2^{\circ}$ resolution from $9.3^{\circ} \mathrm{W}$ to $36.5^{\circ} \mathrm{E}$ of longitude, and from $30^{\circ} \mathrm{N}$ to $46^{\circ} \mathrm{N}$ of latitude, and vertically informed for 26 depths layer (see MEDAR Group, 2002) on a non-linear scale between 0 and the seafloor (maximum depth of 5,267m). Each annual climatology used in the present study was calculated using the same methodologies (MEDAR Group, 2002). Additional environmental parameters were also added to the dataset from the literature (D'Ortenzio et al., 2005; Henson et al., 2012; Morel et al., 2007; Reygondeau and Beaugrand, 2011). This addition of environmental parameters aimed at describing the vertical physical composition of the water column using: Mixed Layer Depth, thermocline, euphotic depth or transport of organic matter. Each environmental parameter represented an annual average and was spatially resolved on the same horizontal and vertical resolution as the MEDAR/MEDATLAS parameters (see Table 1).

In addition, raw values were standardized to reduce the effects of environmental parameters amplitude of variation (i.e. variance) on the clustering methodologies (Legendre \& Legendre, 1998). Nonetheless, it is important to keep in mind that there are under-sampled areas in the MS, especially in the southern parts of the basin. Therefore, the results could be biased by the low quality of the observation in these regions. Also, since the temporal fluctuations of each environmental parameter gathered was not available, no time series analysis was performed. 


\subsection{Statistical Methodologies}

We aimed at identifying biogeochemical regions in the MS (sensu Longhurst, 2007), relying on an exhaustive set of environmental parameters resolved in both horizontal and vertical dimensions, using a procedure based on the methodology developed by Oliver et al. (2004). Each step of the methodology is summarised in supplementary Fig. 2.

\subsubsection{Vertical partition of the MS.}

The vertical dimension of the basin was subdivided into 4 layers, 3 representing the pelagic environment (epipelagic, mesopelagic and bathypelagic) and 1 the seafloor. The boundaries separating each pelagic layer were adapted from the original definition retrieved in the literature (Hardy, 1956; Pérès, 1961; Pérès and Devèze, 1963). Contrary to the original boundaries' definitions that suggested constant vertical divisions at $200 \mathrm{~m}, 1000 \mathrm{~m}$ and the depth of the seafloor, we used the approach that accommodates the spatial heterogeneity of the water column. Depth of the seafloor layer was here defined on the bathymetry values for each grid cell.

To summarise the approach (step. 1, Supplementary. Fig. 2), the boundary between the epipelagic and the mesopelagic layers was defined as the depth where the environmental conditions do not allow any primary production (Behrenfeld, 2010; Sverdrup, 1953). Since vertical profiles of net primary production were not available for the whole basin, this depth was approximated at the shallowest depth between the euphotic zone and the mixed layer depth, for each geographical cell of the basin. The annual climatology of the epipelagic/mesopelagic boundary is mapped on Fig. 1a. 
As there is presently no common definition for the mesopelagic/bathypelagic boundary in the literature across oceanographic disciplines, we here considered the gradient of the Flux of Particulate Organic Carbon (FPOC). Indeed, since the calculation of FPOC uses temperature and salinity profiles, surface chlorophyll-a concentrations and are calibrated using POC values from sediment trap (Henson et al., 2012), the FPOC product represents a biogeochemical merge of the main vertical gradients in the water column. Therefore, depth of the boundary between the mesopelagic and the bathypelagic environment was defined as the depth where 5 consecutive FPOC concentrations show no significant change. First, each profile was interpolated every 5 metres between 0 and $5000 \mathrm{~m}$ (spline interpolation; Legendre and Legendre, 1998). Second, the derivative function of FPOC against depth was computed and the depth of the boundary was set at the depth where the decrease of FPOC between 5 consecutive points was not significantly different from the previous iteration (t-test, $\mathrm{p}$ value $>0.05$ ). The resulting depth of the boundary is mapped in Fig. 1b. Also, a test in each MEOWS has been performed to test if the interpolation of the FPOC did not alter the value of the depth boundary. Finally, the boundary between the bathypelagic and the seafloor was set using the bathymetry of the basin mapped on Fig. 1c.

\subsubsection{Characterisation of the environmental conditions of the pelagic and seafloor layers}

Based on the gathered environmental dataset (described in 2.1 and Table 1, and here named $\left.\mathrm{X}_{\text {all }}\right)$, a vertical average was computed within each pelagic vertical range to depict the mean environmental conditions in the pelagic and seafloor layers (step 2.1, Supp. Fig. 2). Four distinct environmental matrices were thus calculated: (1) between $0 \mathrm{~m}$ and the depth of the epipelagic/mesopelagic boundary (Fig.1a) for the epipelagic layer (i.e. $\mathrm{X}_{\text {epipeligagic }}$ ); (2) 
between the epipelagic/mesopelagic and the mesopelagic/bathypelagic boundaries (Fig. 1b) for the mesopelagic layer $\left(\mathrm{X}_{\text {mesopelagic }}\right)$; (3) between mesopelagic/bathypelagic and the seafloor (Fig. 1c) for the bathypelagic layer ( $\left.\mathrm{X}_{\text {bathypelagic }}\right)$; (4) at the seafloor level ( $\mathrm{X}_{\text {seafloor }}$ ). In addition, the annual climatology of the non-vertically discretised environmental variables indicating the water column stability (euphotic depth, mixed layer depth, wind speed, intensity and depth of the thermocline) were added to the $\mathrm{X}_{\text {epipelagic }}$ and $\mathrm{X}_{\text {mesopelagic }}$ matrices. The bathymetry was added to $\mathrm{X}_{\text {seafloor }}$ to account for the basin's topography and better depict the different types of benthic habitats. Spatial distributions of each parameter for each layer can be retrieved on Supplementary Fig. 4, 5, 6 and 7.

To characterise the main environmental parameters driving the spatial variance of each layer (step 2.2, Supp. Fig. 2), a Principal Component Analysis (PCA; Jolliffe, 1986) was performed on the environmental matrix of each layer. The first and second components (i.e. coordinates values of each geographical cells in each PCA dimension) of each PCA are mapped on Fig. 2 as well as the result of the PCA.

\subsubsection{Identification of the spatial distribution of the BGCR}

To identify an objective environmental spatial division, the methodology proposed by Oliver et al. (2004) was applied (step 2.3, Supp. Fig. 2). This numerical procedure uses 4 types of clustering methodologies, here applied on each of the normalised matrices X: (1) Kmeans (Hartigan and Wong, 1979), (2) C-means (Quackenbush, 2001), (3) agglomerative with Ward linkage (Ward, 1963), and (4) with complete linkage (Legendre and Legendre, 1998) (step 2.2; Fig. 1). The 4 types of clustering algorithms were selected from Oliver et al. (2004) according to their ability to synoptically group similar environmental variables. Each 
method was combined owing to their different but complementary ways to handle low dissimilarity clusters (i.e. sensible cluster). Each clustering algorithm was run to retrieve between 2 and 50 clusters, based on the Euclidian distance. The C-means and K-means were repeated 999 times per iteration and the most frequently retrieved division was selected.

The next step of this methodology was dedicated to the identification of the optimal number of clusters (step 2.4, Supp. Fig. 2). The 'Figure Of Merit' (FOM) analysis (Yeung et al., 2001) is used, as recommended by Oliver et al. (2004). It quantifies the variation of the total environmental variance explained between 2 successive numbers of clusters (i.e. here 2 to 50) for each agglomerative clustering method. A small FOM value indicates that the cluster centroid predicts better the other members of its cluster and that the variance within the cluster is comparatively small. A normalised Average Slope Function (ASF) is calculated using the FOM of each clustering methodology to summarise the information. The ASF exhibits a negative exponential decrease with a rapid decrease for the low number of clusters and a slower decrease after a point k of inflexion (represented by dashed black line on Fig. 2). The point $\mathrm{k}$ was considered as the optimal number of clusters because the deviation between cluster means and the individual observations in each cluster becomes very small (Oliver et al., 2004). The point $\mathrm{k}$ is the threshold of acceptable flatness (TAF), which is defined as the first number of clusters where the decrease is inferior to $1 \%$ of the maximum ASF for 3 consecutive clusters. The FOM, ASF and TAF analyses were represented on Supp. Fig. 3.

The step 2.5 of the numerical procedure aimed to identify an objective distribution of the BGCR. The strength of the boundaries (named effectiveness; Oliver et al, 2004), as identified by each clustering methodology, was first computed by taking into account all delineation from 2 to $\mathrm{k}$ clusters. Indeed, for every iteration, $\mathrm{K}$-means and $\mathrm{C}$-means procedures 
modify the spatial distribution (i.e. number of clusters imposed by the operator), as these methodologies divide objectively the space in accordance to the centres of inertia detected. The map of the effectiveness (Fig. 3b, 4b, 5b and 6b) represents the percentage of a boundary retrieved in a given geographic cell for each methodology and from 2 to k clusters.

The last step of the procedure identified a compromise distribution of the clusters determined by the 4 methods. Contrary to the procedure of Oliver et al. (2004) that sums the clusters number retrieved with all clustering methodologies used, we here attempted to find a trade-off between all the obtained spatial partitions. To do so, we used a methodology called "watershed" (Meyer, 1994), implemented from imagery analysis. The watershed function uses the environmental variance within each cluster computed with all methodologies at $\mathrm{k}$ (optimal number of clusters defined with FOM) and tests the environmental difference between clusters (Kruskall-Wallis, see Legendre \& Legendre, 1998). All clusters showing non-significant differences in their environmental variance were spatially merged by taking into account the spatial distribution of the boundary effectiveness. The procedure stops once $\mathrm{k}$ clusters are retrieved. The resulting objective distribution of the BGCRs for each layer is shown in Fig. 3a, 4a, 5a and 6a. Values of the parameters contributing the most to the PC1 and PC2 (see 2.2.3) were computed using the vertical range and spatial distribution of each BGCR identified. These environmental profiles are represented as violin plots on Fig. 3c, 4c, $5 \mathrm{c}$ and $6 \mathrm{c}$.

\subsubsection{Comparison of the environmental profiles of all pelagic BGCRs}

To examine the differences in the environmental profile (multivariate environmental variation) of each BGCR of each pelagic layer, the mean and standard deviation of each 
parameter of $\mathrm{X}_{\text {epipelagic, }} \mathrm{X}$ mesopelagic and $\mathrm{X}$ bathypelagic were calculated. Only the parameters common to all environmental matrices were considered here: temperature, salinity, nitrates, nitrites, orthophosphate, silicates, $\mathrm{pH}$, Chlorophyll-a concentration, and dissolved oxygen concentration. A PCA was performed on the computed data, and the position of each BGCR was plotted in the dimension of the PC1 and PC2 (Fig. 7). BGCRs located on the seafloor, in the Marmara Sea or in the Atlantic Ocean were not considered in this analysis as they represent non-Mediterranean areas, and thus could bias the PCA analysis and the comparison between MS BGCRs.

\section{Results}

\subsection{Vertical division of the Mediterranean pelagic realm}

Using the shallowest depth between the mixed layer depth and the euphotic depth, the annual climatology of the epipelagic/mesopelagic boundary is found to vary between $10 \mathrm{~m}$ and $75 \mathrm{~m}$ (Fig. 1a). The deepest boundaries are found in open sea areas, covering most of the oriental basin and the Tyrrhenian Sea. These areas are oligotrophic with low detritus concentration allowing deeper light penetration. In contrast, the more productive areas located in the occidental basin and continental shelf areas exhibit shallower depth of the epipelagic/mesopelagic boundary. In those regions, the waters above $200 \mathrm{~m}$ are more 'turbid' resulting in shallower epipelagic layer than in tropical areas (Fig. 1a).

The annual climatology of the lower boundary separating the mesopelagic and the bathypelagic layers (Fig. 1b) varies between $140 \mathrm{~m}$ and $1500 \mathrm{~m}$. The areas with the deepest mesopelagic boundary are located in open sea areas of low biological 
activity. The vertical distribution of this boundary appears to be strongly influenced by the basin's bathymetry (i.e. that defines the seafloor depth) with the deepest boundaries following the shape of the deep-sea basins (Fig. 1c).

\subsection{Environmental and spatial characterisation of the BGCRs}

60 biogeochemical regions are identified within the MS. Pelagic layers exhibit a similar number of clusters: 12 for the epipelagic, 12 for the mesopelagic, 13 for the bathypelagic while the seafloor is partitioned by 26 biogeochemical regions. Each vertical layer is here divided into a specific number of BGCRs, each one characterised by a spatial distribution with a given strength of boundaries and a specific environmental range (Figures 3 to 6). BGCRs represent either significant multivariate shifts along the environmental gradient, or local features driven by changes in only one variable. To simplify the description of each BGCR, only key environmental parameters are represented on Figures 3 to 6 (right panels) according to the analysis described in Figure 2.

\subsubsection{The Epipelagic layer}

The epipelagic layer is partitioned into 12 BGCRs (Fig. 3). 4 BGCRs (1, 2, 7 and 11) subdivide the Western-Eastern environmental gradient depicted on Fig. 2. The strength of the boundary is highly marked in the occidental basin and decreases towards the eastern basin, suggesting a less marked environmental spatial change across the longitudinal environmental gradient. The Adriatic, Aegean or Ligurian Seas are well captured as they exhibit a particular environmental range compared to the longitudinal gradient (i.e. change in the chlorophyll-a concentration) underlined by 
high boundary effectiveness. The Gulf of Trieste and the Algerian Coast (i.e. BGCR 3) are also well characterised by high concentration of $\mathrm{NO}_{2}$.

\subsubsection{The mesopelagic layer}

The mesopelagic layer is partitioned into 10 strictly Mediterranean BGCRs (plus one in the adjacent North Atlantic Ocean, and one in the Marmara Sea). The mesopelagic BGCRs differ environmentally and spatially from those found in the epipelagic layer, especially in the Western Basin. Additionally, their mapping (Fig. 4) reveals a patchier distribution pattern. This pattern can be attributed to the strength of the water-column stratification index (i.e. thermocline depth variable, see Fig. 2). For instance, the NW part of the MS is subdivided into 5 regions (i.e. 1, 2, 4, 6 and 8) while the epipelagic layer is subdivided into 3 BGCRs. The patchiest areas exhibit the highest values of boundary effectiveness (Fig. $4 \mathrm{~b}$ ). The $6^{\text {th }}$ BGCR represents the region where the bathymetry is too shallow for the existence of a bathypelagic area. In the oriental basin, the mesopelagic layer shows a general partition similar to the one encountered in the epipelagic layer, with Ionian Sea, Levantine Basin and Aegean Sea being distinguished by low values of effectiveness.

\subsubsection{The bathypelagic layer}

The bathypelagic layer is divided into 12 BGCRs within the MS (Fig. 5). Large BGCRs are found for all the MS characterising the longitudinal environmental gradient (see Fig. 2 and Supplementary Figs. 4 to 7). The latitudinal divisions marked by low values of effectiveness of the boundaries are depicted in the large regions of 
the western basin (BGCRs 9 and 10) and of the eastern basin (BGCRs 12 and 13) due to slight differences in $\mathrm{SiO}_{2}$ concentrations.

\subsubsection{The seafloor layer}

Along the topography of the MS, several distinct environmental conditions within this layer can be identified such as the coastal system, i.e. the slope or the deepsea environment resulting in the most important range of variation in all the parameters considered in the study. For example, nitrate concentrations exhibit huge variations ranging from undetected concentrations up to 9 mmol. $\mathrm{l}^{-1}$ (Fig. 6c). Regional environmental features for similar depths ranges show important differences (nitrates ultimately influence the partitioning of the BGCRs; for example, BGCRs 2 and 4 that have about the same depth, present a twofold difference in $\mathrm{NO}_{3}$ concentrations). Consequently, high variations in environmental conditions, which are linked to the bathymetric gradient, combined with basin-wide environmental patterns, and local specificities, results in a very patchy distribution of a higher number of BGCRs in the seafloor layer.

\subsection{Comparison of Mediterranean pelagic BGCRs environmental conditions}

In order to compare the environmental conditions of all the Mediterranean pelagic BGCRs together, a PCA was performed (Fig. 7). Most of the total environmental variance was supported by the vertical position of the BGCRs along the water column $(\mathrm{PC} 1=40.9 \%)$. BGCRs are well sorted from the bathypelagic layer to the epipelagic layer along the PC1. This sorting shows that environmental conditions are more structured along the vertical than along the horizontal dimension. For 
instance, geographically adjacent BGCRs in different layers (for example BGRs 4E, $10 \mathrm{M}$ and $6 \mathrm{~B}$ in the Levantine area) exhibit highly different environmental conditions and hence, projected in distinct locations in the PCA dimensions.

The second component depicts the environmental longitudinal gradient over the basin. For instance, the BGCRs located in the western basin are found in the negative part of the PC2 axis, while the BGCRs in the eastern basin are in the positive part. Also, on the PCA representation, the maximal distance between representative BGCR points within the bathypelagic layer appears smaller compared to the BGCRs of the pelagic layers. This implies that the BGCRs of the bathypelagic layer are more environmentally homogeneous compared to the BGCRs of the upper layers, because of a decreasing environmental gradient with depth (as depicted in Fig. 2 a-b-c). This analysis reveals that vertically adjacent BGCRs do display highly similar environmental conditions such as the epipelagic Ligurian regions (BGCR 9E) and the mesopelagic Adriatic region (BGCR 6M).

\section{Discussion}

Ecological divisions of the Oceanic realm generally aim at providing an objective geographical framework that delineates the environmental and biotic characteristics of a given area. Presently, most of the regional or global divisions proposed in the literature (i.e. for the MS: Sherman, 2005; Spalding et al., 2007; Longhurst, 2007; D'Ortenzio and Ribera D'Alcalã, 2009; Berline et al., 2014; Rossi et al., 2014) are based on a limited number of environmental parameters that are often representative of the surface waters (Reygondeau et al., 2013). Such environmental selection is attributed to the difficulty in gathering large multivariable datasets resolved in both 
the horizontal and vertical dimensions. As the epipelagic layer only represents less than $10 \%$ of the global ocean, one could argue that former partitions might provide a limited picture of the complexity of the whole system (Robinson et al., 2010; Webb et al., 2010).

The spatial partitioning of the epipelagic layer (Fig. 3) identified 12 BGCRs. This study used a larger number of environmental parameters than previous ones (hydrodynamic constraints (Rossi et al., 2014; Berline et al., 2014), chlorophyll phenology (D’Ortenzio and D’Alcala, 2009), biophysical parameters including mesoscale processes (Nieblas et al., 2014). All studies found surface partitions of similar spatial distributions. Such similarities are not surprising since the division of the shallowest waters (between 0 and $70 \mathrm{~m}$, see Fig. 1) is indeed driven by the strong longitudinal gradient in temperature, salinity and chlorophyll-a concentration (Figure 2), parameters that were used in the previous studies. The finding of a common trend in the distribution of all proposed environmental partitions of the epipelagic zone, while using different sets of parameters and methodologies, strongly supports (i) the robustness of previous partitions, and (ii) the need for only a classic and simple set of environmental parameters in order to partition that layer.

The longitudinal environmental gradient driving the epipelagic division is also found in other pelagic layers (Figure 2). However, the interval of variation and the contribution of all the considered parameters changes with depth (Figure. 2). Indeed, the PCA (Fig. 7) reveals that environmental dissimilarity between the BGCRs within a pelagic layer decreases with 
depth. The BGCRs' delineation provided for the mesopelagic or the bathypelagic layers appears less influenced by the longitudinal gradient of classical parameters (temperature, salinity and chlorophyll), and more impacted by other variables such as vertical mixing, nutrient concentrations or bathymetry (Figure 2.). For instance, the mesopelagic layer shows a patchier pattern than the epipelagic layer, especially in the western basin where most of the water convection areas occur (The MerMex Group, 2011). The bathypelagic layer, being relatively isolated from winter convection, and thus from the influence of atmospheric interactions, is mostly partitioned according to deep-water circulation and morphological features. Partitioning of the seafloor layer is mostly driven by the bathymetric gradient with a strong environmental opposition between coastal, slope and deep-sea regions but also by the longitudinal environmental gradient, to a lesser extent.

These results reveal that the use of parameters such as temperature, salinity and chlorophyll in biogeographical studies are sufficient to capture most of the environmental variance of the MS, hence providing a realistic delineation of the surface waters. Nonetheless, since the environmental variance is not supported by the same set of parameters with the depth (Figure. 2), environmental partitioning of a given layer cannot be projected to another one due to the non-congruence of the BGCRs delineation between vertical layers.

The MS is composed of a large number of biotopes that can be represented as a 3D jigsaw puzzle of biotopes each driven by a specific set of environmental parameters. The 3D partition can thereby be interpreted as an annual average of the different environmental biotopes that can be encountered in the whole basin. Each of those environmental envelopes delineates a BGCR defined by a given interval of variation for each of the biogeochemical 
and physical parameters considered. Odum (1971) defined such ecological units, or ecosystems, as intervals of variation among all the environmental possibilities where an assemblage of adapted species can develop and maintain their population.

BGCRs are separated by boundaries where effectiveness reflects the intensity of exchanges in between two adjacent regions. Therefore, exchanges of energy and/or matter characterise the interactions in between BGCRs (Odum, 1971). The strength of those exchanges could here be approximated by the map of boundary effectiveness provided for each layer on an annual basis. The lower the yearly averaged index is, the more the adjacent provinces present an overlap of environmental envelopes, which suggests exchange of matter or energy (Reygondeau et al., 2013).

The Mediterranean is known to exhibit strong interactions of physical processes that act on a large spectrum of spatial and temporal scales and that directly impact the ecosystem dynamics (The MerMex Group, 2011). Maps of the boundary effectiveness (Fig. 5b, 6b and 6c) for the pelagic layers coincide with the complex dynamic features of the thermohaline circulation over the MS such as currents, fronts and sub-mesoscale structures (Millot and Taupier-Letage, 2005; Rossi et al., 2014; Berline et al., 2014). High values of boundary effectiveness correspond to regions of low interactions such as gyre cores, closed coastal systems or fronts. High mesoscale features characterise surface waters in the MS, in particular along the African shelf (Millot and Taupier-Letage, 2005). There, BGCRs boundaries (for example along the Tunisian and Libyan coasts) follow the anticyclonic eddies that characterise the whole area: in this way, the shape of the BGCR 5 in the epipelagic layer reflects the $50-150 \mathrm{~km}$ chlorophyll-poor circular structures. It is thus not surprising that our 
analysis finds that effectiveness of boundaries are closely related to well recognized dynamic features (Rossi et al., 2014; Berline et al., 2014).

The statistical approach to partitioning should not prevent biogeochemical interpretation. A closer look at the regions that show high environmental similarities could be interpreted together as a "nested environmental system". For instance, in the epipelagic layer, BGCR 2 and 4 show a short distance in the PCA dimensions indicating that a single region could actually be enough to characterise half of the eastern basin well. A similar possible reduction in the number of BGCR, using results from PCA (Fig. 7), can also be made for the mesopelagic. Merging short distance BGCR in this layer would result in a large region covering most of the eastern basin (BGCR 5 and BGCR 10). Similarly, the very close similarity between BGCR 1 and 8 also leads to a simplification of the regions in the most western MS. In the bathypelagic layer, BGCR 12 and 13 are also very similar and a single region could rather be retained, corresponding to the whole Ionian Sea. This fine analysis of the environmental variance indicates thus that a slightly lower number of BGCRs could be sufficient to capture the full 3D environment of the MS in a more global analysis.

\section{Conclusion and perspective}

Past divisions of ocean have never fully the full of physical, chemical and biotic complexity of this realm. This bias is historically driven by data availability at the spatial scale of the study (global, Oceanic basin, regional) together with the topic of interest of the authors (ecology, biogeochemistry, economics or politics). So far, studies attempting to investigate the benefits of a multivariate and multidimensional 
approach are scarce. Here we considered the multivariate approach over the whole water column to propose a 3D partition of the MS environmental conditions.

The present study show that the distribution of the boundaries is closely related to well recognized oceanographic dynamic features of the basin. This confirms the importance of considering a highly resolved environmental dataset to account for meso-scale processes that drive most of the MS spatial and vertical biogeochemical variability. We also confirmed that a classical set of environmental parameters (temperature, salinity and chlorophyll), used in most of the previous studies, is sufficient to partition the epipelagic layer since it is mostly driven by the westerneastern gradient in the MS but their influence decreases with depth. Thus, other environmental parameters are needed to characterise specific deep water conditions that are driven by different biogeochemical processes compared to the epipelagic layer. This study clearly revealed the crucial need for a multidimensional and multivariate approach to model spatial distribution of deep or vertical migrating species. This is of major importance for conservation management as we show that one cannot rely only on surface or bottom parameters to delineate an optimal zone for marine conservation.

These multivariate and multidimensional approaches represent the first step towards a partition that copes with the full complexity of the MS. Indeed, the approach proposed in the present study only coped with 1 of the 2 components of an ecosystem: the biotope (sensu Odum, 1974). The next step towards an optimal ecosystem division is thereby an extension of the present study to species community 
distribution and trophic linkage to provide a useful geographic framework for ecosystem management planning (fisheries quotas, biodiversity conservation planning or implementation of marine protected areas).

\section{Acknowledgments}

This work is a contribution to the EC FP7 PERSEUS Project (Policy-oriented marine Environmental Research in the Southern EUropean Seas; Grant. Agr. 287600). A post-doctoral research grant provided by the PERSEUS Project supported GR. The authors wish to also thank the MISTRALS-MERMEX program (Institut des Sciences de l'Univers, INSU), as a contribution to the Surface Ocean - Lower Atmosphere Study (SOLAS), the Integrated Marine Biogeochemistry and Ecosystem Research (IMBER) and the LOICZ (Land-Ocean Interactions in the Coastal Zone) projects. G.R would also aknowledge the support from the Nippon Foundation-the University of British Columbia (UBC) Nereus Program. The authors would like to thank Lindsay Lafreniere for her help in the editing of the manuscript. We also thank the 3 anonymous reviewers who helped to improve this manuscript. This work is dedicated to the memory of our colleague and friend Frederic Ibañez. 


\section{References}

Behrenfeld, M.J., 2010. Abandoning Sverdrup's Critical Depth Hypothesis on phytoplankton blooms. Ecology, 91, 977-989.

Berline, L., Rammou, A.-M., Doglioli, A., Molcard, A., Petrenko, A., 2014. A ConnectivityBased Eco-Regionalization Method of the Mediterranean Sea. PloS one, 9, e111978.

Cuttelod, A., García, N., Malak, D.A., Temple, H.J., Katariya, V., 2009. The Mediterranean: a biodiversity hotspot under threat. Wildlife in a Changing World-An Analysis of the 2008 IUCN Red List of Threatened Species, 89.

D'Ortenzio, F., Iudicone, D., de Boyer Montegut, C., Testor, P., Antoine, D., Marullo, S., Santoleri, R., Madec, G., 2005. Seasonal variability of the mixed layer depth in the Mediterranean Sea as derived from in situ profiles. Geophysical Research Letters, 32.

D'Ortenzio, F., Ribera D'Alcalã, M., 2009. On the trophic regimes of the Mediterranean Sea: a satellite analysis. Biogeosciences, 6, 139-148.

The MerMex Group, 2011. Marine ecosystems' responses to climatic and anthropogenic forcings in the Mediterranean. Progress in Oceanography, 91, 97-166.

Gabrié, C., Lagabrielle, E., Bissery, C., Crochelet, E., Meola, B., Webster, C., Claudet, J., Chassanite, A., Marinesque, S., Robert, P., 2012. Statut des Aires Marines Protégées en mer Méditerranée. MedPAN and CAR/ASP (pp. 1-260).

MEDAT Group, 2002. MEDATLAS/2002 database. Mediterranean and Black Sea database of temperature, salinity and bio-chemical parameters. Climatological Atlas. ( 215 pp). Hardy, A., 1956. The open sea. Its natural history: the world of plankton. London: Collins. Hartigan, J.A., Wong, M.A., 1979. A k-means clustering algorithm. Journal of the Royal Statistical Society Series C, 28, 100-108.

Henson, S.A., Sanders, R., Madsen, E., 2012. Global patterns in efficiency of particulate organic carbon export and transfer to the deep Ocean. Global Biogeochemical Cycles, 26, GB1028.

Jolliffe, I.T., 1986. Principal Component Analysis. New York: Springer-Verlag New York Inc.

Legendre, P., Legendre, L., 1998. Numerical Ecology. Amsterdam : Elsevier Science BV. Longhurst, A., 2007. Ecological geography of the Sea. London: Academic Press. 
Meyer, F., 1994. Topographic distance and watershed lines. Signal processing, 38, 113-125.

Millennium ecosystem assessment, 2005. Millennium Ecosystem Assessment.

Millot, C., 1999. Circulation in the western Mediterranean Sea. Journal of Marine Systems, 20, 423-442.

Millot, C., Taupier-Letage, I., 2005. Circulation in the Mediterranean Sea. The Mediterranean Sea (pp. 29-66): Springer.

Morel, A., Huot, Y., Gentili, B., Werdell, P.J., Hooker, S.B., Franz, B.A., 2007. Examining the consistency of products derived from various Ocean color sensors in open Ocean (Case 1) waters in the perspective of a multi-sensor approach. Remote Sensing of Environment, 111, 69-88.

Moutin, T., Van Wambeke, F., Prieur, L., 2012. Introduction to the Biogeochemistry from the Oligotrophic to the Ultraoligotrophic Mediterranean (BOUM) experiment. Biogeosciences, 9, $3817-3825$.

Nieblas, A. E., Drushka, K., Reygondeau, G., Rossi, V., Demarcq, H., Dubroca, L., and Bonhommeau, S. , 2014. Defining Mediterranean and Black Sea biogeochemical subprovinces and synthetic Ocean indicators using mesoscale Oceanographic features. PloS one, 9 , e111251.

Odum, E.P., 1971. Fundamentals of ecology. Philadelphia: Saunders.

Oliver, M.J., Glenn, S., Kohut, J.T., Irwin, A.J., Schofield, O.M., Moline, M.A., Bissett, W.P., 2004. Bioinformatic approaches for objective detection of water masses on continental shelves. Journal of Geophysical Research, 109, C07S04.

Pérès, J., 1961. La vie benthique. Paris : Presses Universitaires de France.

Pérès, J., Devèze, L., 1963. la vie pélagique. Paris : Presses Universitaires de France.

Quackenbush, J., 2001. Computational analysis of microarray data. Nature Reviews Genetics, 2, 418-427.

Reygondeau, G., Beaugrand, G., 2011. Water column stability and Calanus finmarchicus. Journal of Plankton Research, 33, 119-136.

Reygondeau, G., Longhurst, A., Martinez, E., Beaugrand, G., Antoine, D., Maury, O., 2013. Dynamic biogeochemical provinces in the global Ocean. Global Biogeochemical Cycles, 27 , $1046-1058$.

Robinson, C., Steinberg, D., Anderson, T., Arístegui, J., Carlson, C., Frost, J., Ghiglione, J., Hernández-León, S., Jackson, G.A., Koppelmann, R., 2010. Mesopelagic zone ecology and 
biogeochemistry-a synthesis. Deep Sea Research Part II: Topical Studies in Oceanography, $57,1504-1518$.

Rossi, V., Ser - Giacomi, E., López, C., Hernández - García, E., 2014. Hydrodynamic provinces and Oceanic connectivity from a transport network help designing marine reserves. Geophysical Research Letters, 41, 2883-2891.

Sherman, K., 2005. The Large Marine Ecosystem Approach for Assessment and Management of Ocean Coastal Waters. Sustaining Large Marine Ecosystems: The Human Dimension, 316.

Spalding, M.D., Fox, H.E., Allen, G.R., Davidson, N., FerdaÑA, Z.A., Finlayson, M.A.X., Halpern, B.S., Jorge, M.A., Lombana, A.L., Lourie, S.A., 2007. Marine Ecoregions of the World: A Bioregionalization of Coastal and Shelf Areas. BioScience, 57, 573-583.

Sverdrup, H.U., 1953. On Conditions for the Vernal Blooming of Phytoplankton. ICES Journal of Marine Science, 18, 287-295.

Vierros, M., Bianchi, G., Skjoldal, H., 2008. The Ecosystem approach of the convention on biological diversity. Bianchi G, Skjoldal, editors. The Ecosystem approach to fisheries, 3946.

Ward, J.H., 1963. Hierarchical grouping to optimize an objective function. Journal of the American Statistical Association, 58, 236-244.

Webb, T.J., Vanden Berghe, E., O'Dor, R., 2010. Biodiversity's Big Wet Secret: The Global Distribution of Marine Biological Records Reveals Chronic Under-Exploration of the Deep Pelagic Ocean. PloS one, 5.

Yeung, K.Y., Haynor, D.R., Ruzzo, W.L., 2001. Validating clustering for gene expression data. Bioinformatics, 17, 309-318. 


\section{Tables captions}

Table 1. Spatial resolution, units and reference of the environmental variables used in the study.

\section{Figures captions}

Figure 1. Map of the depth of the vertical boundaries of the water column and seafloor: (a) depth of the vertical limit between the epipelagic layer and the mesopelagic layer, (b) depth of the vertical limit between the mesopelagic layer and the bathypelagic layer, (c) bathymetry (m).

Figure 2. Left Panel: results of the PCA performed on the environmental matrices of each pelagic layer and seafloor (see step 1, Fig. 1). The environmental factors are annotated on the figure using letters standing for: (A) temperature; (B) salinity; (C) dissolved oxygen concentration; (D) chlorophyll-a concentration; (E) $\mathrm{pH}$; (F) nitrate concentration; (G) nitrite concentration; $(\mathrm{H})$ orthophosphate concentration; (I) silicate concentration; (J) mixed layer depth; (K) depth of the thermocline; (L) intensity of the thermocline; $(\mathrm{M})$ euphotic depth, $(\mathrm{N})$ wind speed and $(\mathrm{O})$ bathymetry. Right Panel: map of the value of each grid cell of the coordinate of first and second principal (PC1 and PC2) components of the PCA performed for each environmental matrix.

Figure 3. (a) Map of the spatial distribution of the epipelagic BGCRs and (b) associated effectiveness of the boundaries. (c) Violin plots representing the intervals 
of variation of temperature, Chlorophyll-a concentration, intensity of the thermocline and mixed layer depth within each epipelagic BGCR identified (from 1 to 12).

Figure 4. (a) Map of the spatial distribution of the mesopelagic BGCRs and (b) associated effectiveness of the boundaries. (c) Violin plots representing the intervals of variation of dissolved oxygen concentration, temperature, orthophosphate concentration and depth of the thermocline within each mesopelagic BGCR identified (from 1 to 12).

Figure 5. (a) Map of the spatial distribution of the bathypelagic BGCRs and (b) associated effectiveness of the boundaries. (c) Violin plots representing the intervals of variation of dissolved oxygen concentration, salinity, nitrate and orthophosphate concentration within each bathypelagic BGCR identified (from 1 to 13).

Figure 6. (a) Map of the spatial distribution of the Seafloor BGCRs and (b) associated effectiveness of the boundaries. (c) Violin plots representing the intervals of variation of temperature, salinity, bathymetry and nitrate concentration within each seafloor BGCR identified (from 1 to 26 ).

Figure 7. Scatter plot of the pelagic BGCRs position according to the principal component analysis performed on the mean and standard deviation of parameters used 
in each layer. E: position of the epipelagic BGCRs; M: position of the mesopelagic BGCRs; B: position of the bathypelagic BGCRs.

Supplementary Figure 1. Map of the geography of the Mediterranean Basin.

Supplementary Figure 2. Schematic representation of the numerical procedures used in this study (see Materials and Methods for details). All maps presented on step 2 and 3 are computed only for the epipelagic layer.

Supplementary Figure 3. Plots of the Figure Of Merit (FOM), Average Slope Function (ASF, dark line) and Threshold of Acceptable Flatness (TAF, black dashed line) for each vertical layer considered in the study and for different clustering methods: agglomerative clustering methodology with complete linkage in grey, agglomerative clustering methodology with Ward linkage in cyan, K-means in blue, and C-means in green.

Supplementary Figure 4. Maps of the annual climatology of temperature, salinity and chlorophyll-a concentration for each identified layer

Supplementary Figure 5. Maps of annual climatology of $\mathrm{NO}_{3}, \mathrm{PO}_{4}$ and $\mathrm{SiO}_{2}$ concentration for each identified layer

Supplementary Figure 6. Maps of annual climatology of dissolved Oxygen concentration, $\mathrm{pH}$ and $\mathrm{NO}_{2}$ concentration for each identified layer. 
Supplementary Figure 7. Maps of annual climatology of the depth and intensity of the thermocline, Mixed layer depth, Euphotic depth and wind speed 


\section{Table}

\begin{tabular}{|c|c|c|c|c|}
\hline $\begin{array}{l}\text { Environmental } \\
\text { parameters }\end{array}$ & Spatial resolution & unit & reference & source \\
\hline Temperature & $0.2^{\circ} \times 0.2^{\circ}$ & ${ }^{\circ} \mathrm{C}$ & \multirow{9}{*}{$\begin{array}{c}\text { MEDAR Group } \\
2002 \\
\text { MEDATLAS/2002 } \\
\text { database }\end{array}$} & \multirow{9}{*}{$\begin{array}{c}\text { http://www.ifre } \\
\text { mer.fr/sismer/pr } \\
\text { ogram/seasearch } \\
\text { /htql/prj_edmerp } \\
\text {.htql?CPRJ=MA } \\
\text { S3M }\end{array}$} \\
\hline salinity & $0.2^{\circ} \times 0.2^{\circ}$ & PSU & & \\
\hline $\begin{array}{l}\text { chlorophyll-a } \\
\text { concentration }\end{array}$ & $0.2^{\circ} \times 0.2^{\circ}$ & millimole.m-3 & & \\
\hline NO2 concentration & $0.2^{\circ} \times 0.2^{\circ}$ & millimole.m-3 & & \\
\hline NO3 concentration & $0.2^{\circ} \times 0.2^{\circ}$ & millimole.m-3 & & \\
\hline PO4 concentration & $0.2^{\circ} \times 0.2^{\circ}$ & millimole.m-3 & & \\
\hline SIO4 concentration & $0.2^{\circ} \times 0.2^{\circ}$ & millimole.m-3 & & \\
\hline $\begin{array}{l}\text { Dissolved oxygen } \\
\text { concentration }\end{array}$ & $0.2^{\circ} \times 0.2^{\circ}$ & ml.1-1 & & \\
\hline $\mathrm{pH}$ & $0.2^{\circ} \times 0.2^{\circ}$ & & & \\
\hline Bathymetry & $0.2^{\circ} \times 0.2^{\circ}$ & $\mathrm{m}$ & $\begin{array}{l}\text { Smith \& Sandwell, } \\
1997\end{array}$ & www.gebco.net \\
\hline Particular organic flux & $0.5^{\circ} \times 0.5^{\circ}$ & mol.1-1 & $\begin{array}{l}\text { Henson et al., } \\
2012\end{array}$ & NA \\
\hline Euphotic depth & $0.2^{\circ} \times 0.2^{\circ}$ & $\mathrm{m}$ & Morel et al., 2007 & NA \\
\hline Thermocline intensity & $0.5^{\circ} \times 0.5^{\circ}$ & $\mathrm{m}$ & $\begin{array}{l}\text { Reygondeau \& } \\
\text { Beaugrand, } 2011\end{array}$ & NA \\
\hline Thermocline depth & $0.5^{\circ} \times 0.5^{\circ}$ & $\mathrm{m}$ & $\begin{array}{l}\text { Reygondeau \& } \\
\text { Beaugrand, } 2011\end{array}$ & NA \\
\hline Mixed layer depth & $0.5^{\circ} \times 0.5^{\circ}$ & $\mathrm{m}$ & $\begin{array}{l}\text { D'ortenzio et al., } \\
2005\end{array}$ & NA \\
\hline wind speed & $0.2^{\circ} \times 0.2^{\circ}$ & m.h-1 & $\begin{array}{l}\text { Scharton \& } \\
\text { Vujcich, } 1999\end{array}$ & $\begin{array}{l}\text { ftp://podaac- } \\
\text { ftp.jpl.nasa.gov/ } \\
\text { allData/ccmp/L3 } \\
.0 /\end{array}$ \\
\hline
\end{tabular}

Table 1. 
(a)

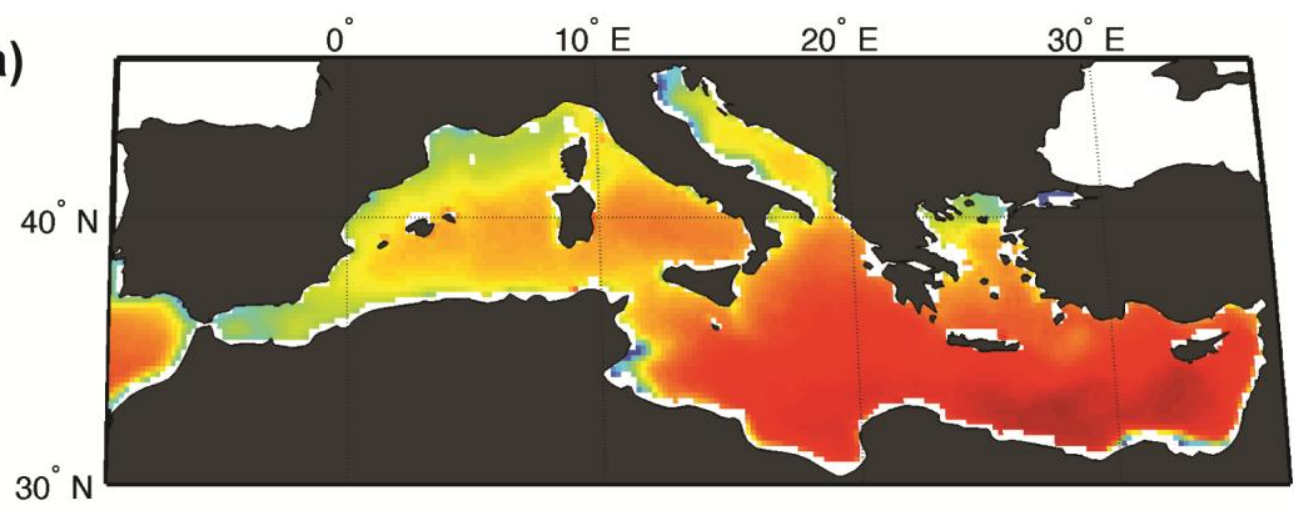

Depth of the epipelagic/mesopelagic boundary $(\mathrm{m})$

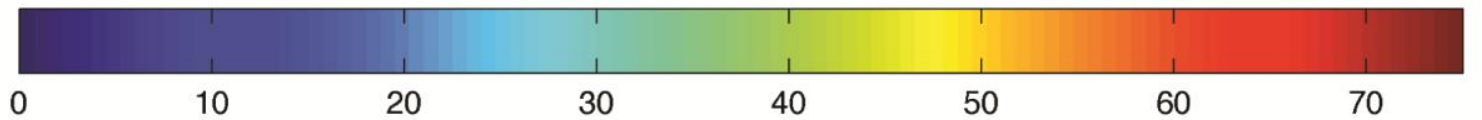

(b)

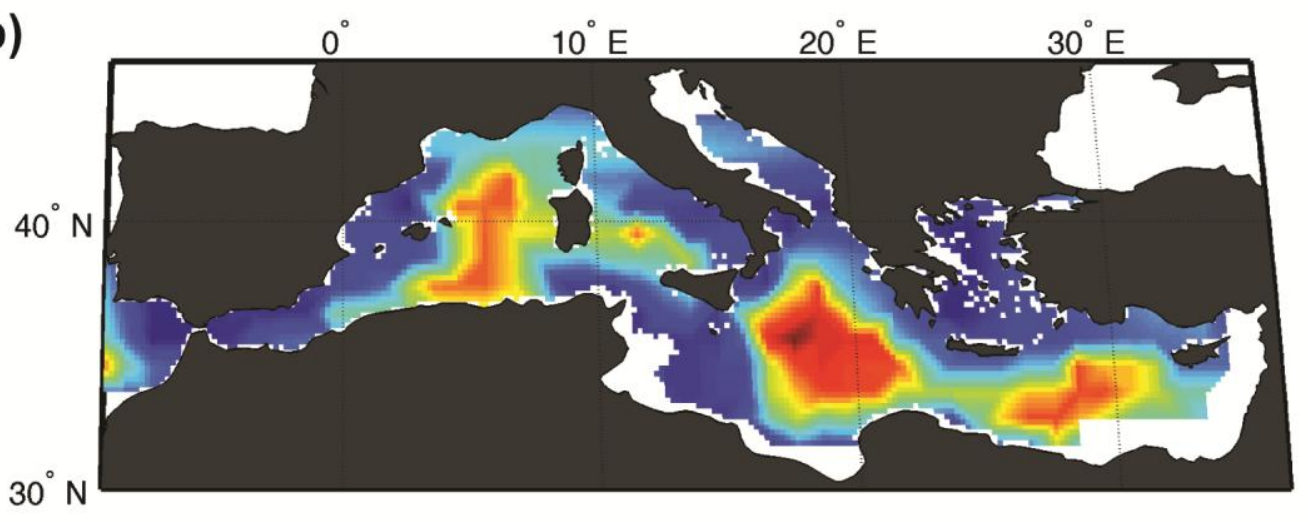

Depth of the mesopelagic/bathypelagic boundary $(\mathrm{m})$

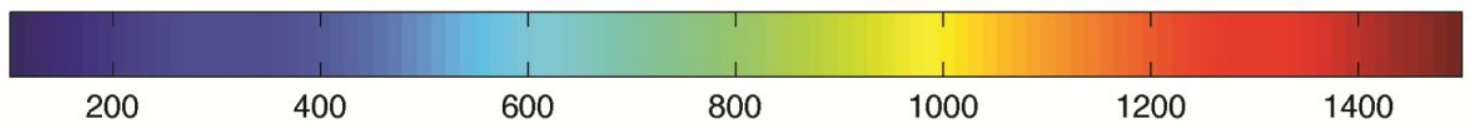

(c)

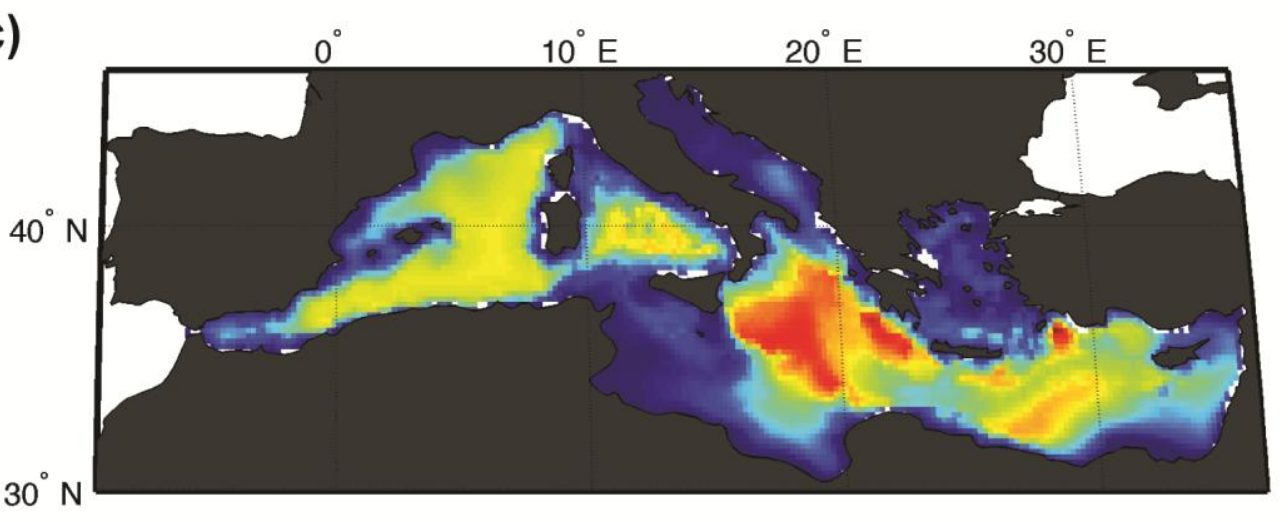

Depth of the seafloor (m)

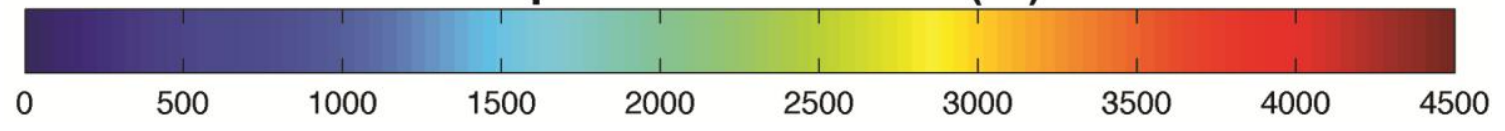




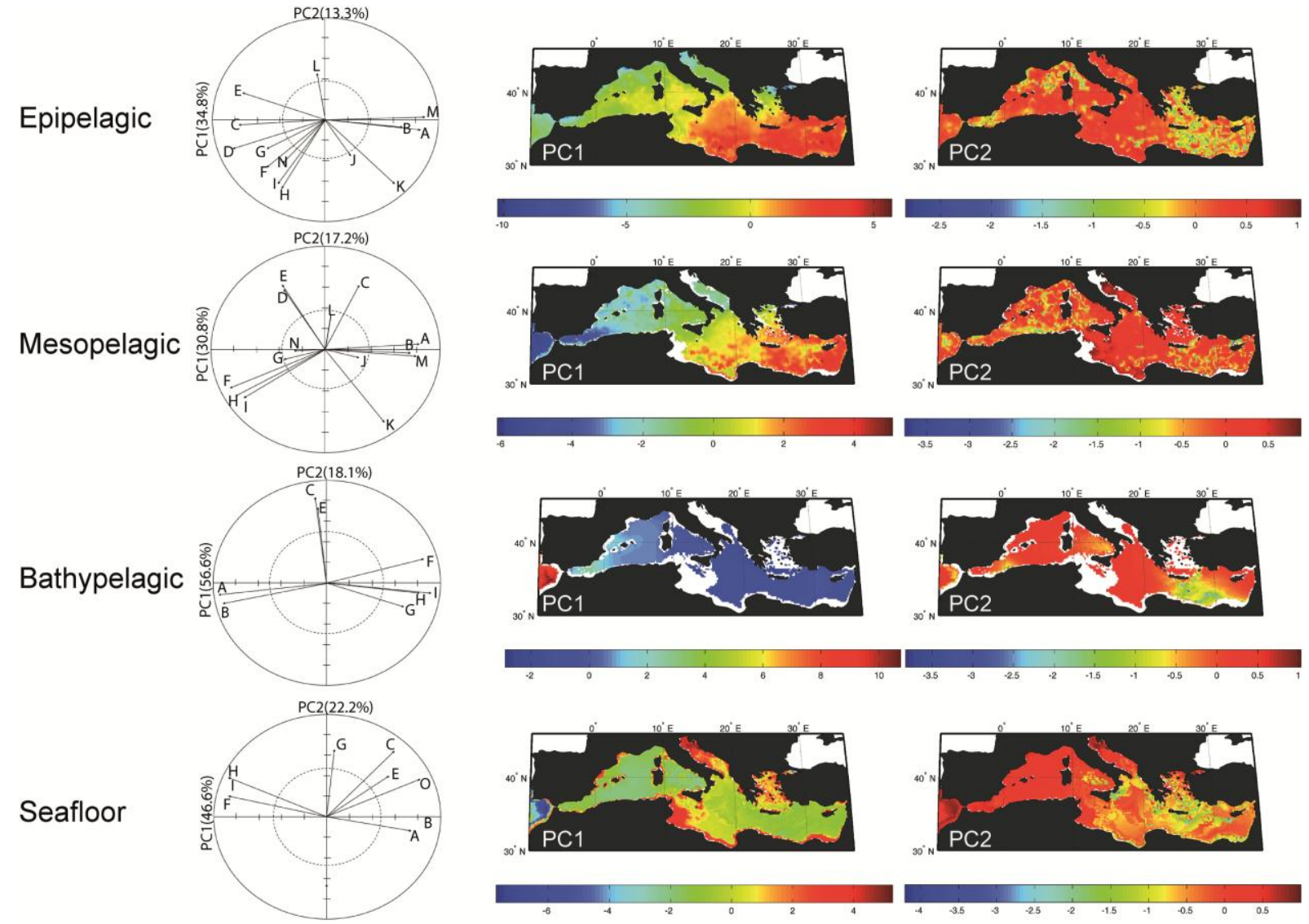



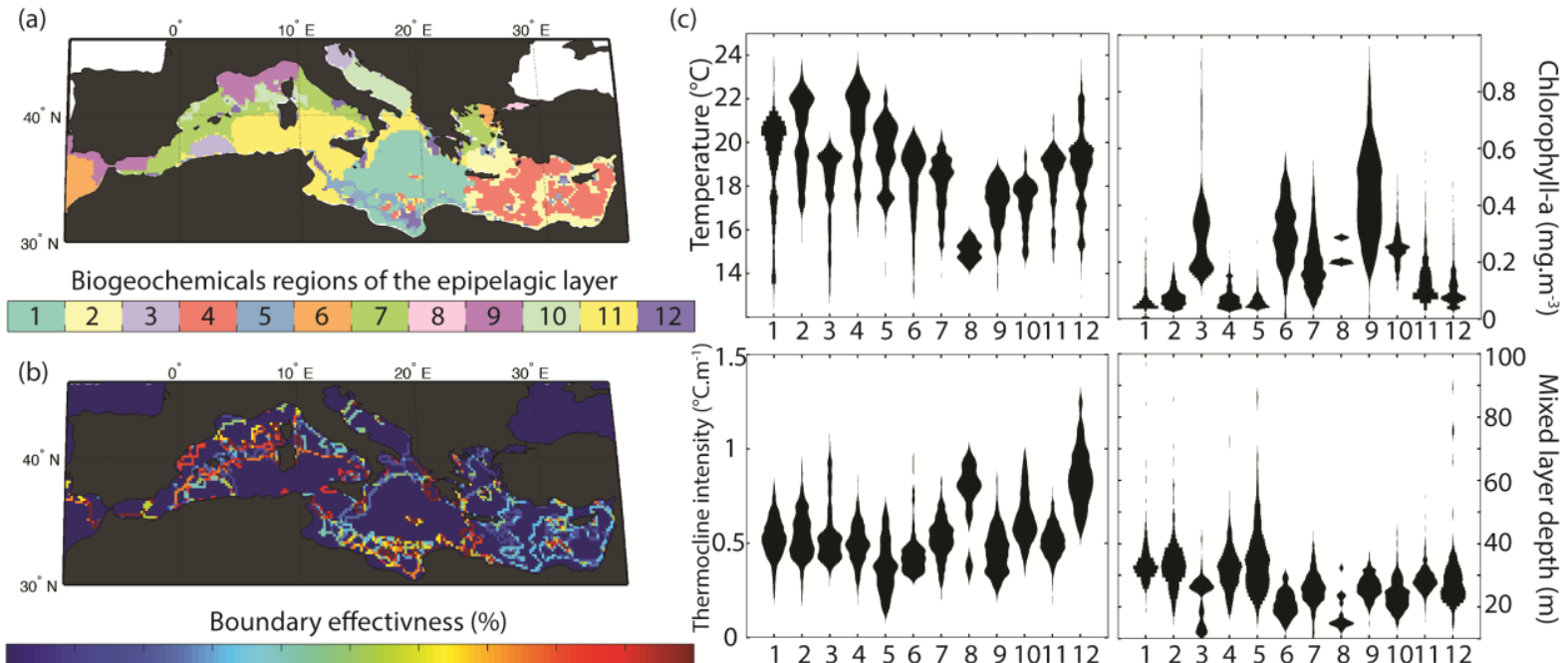

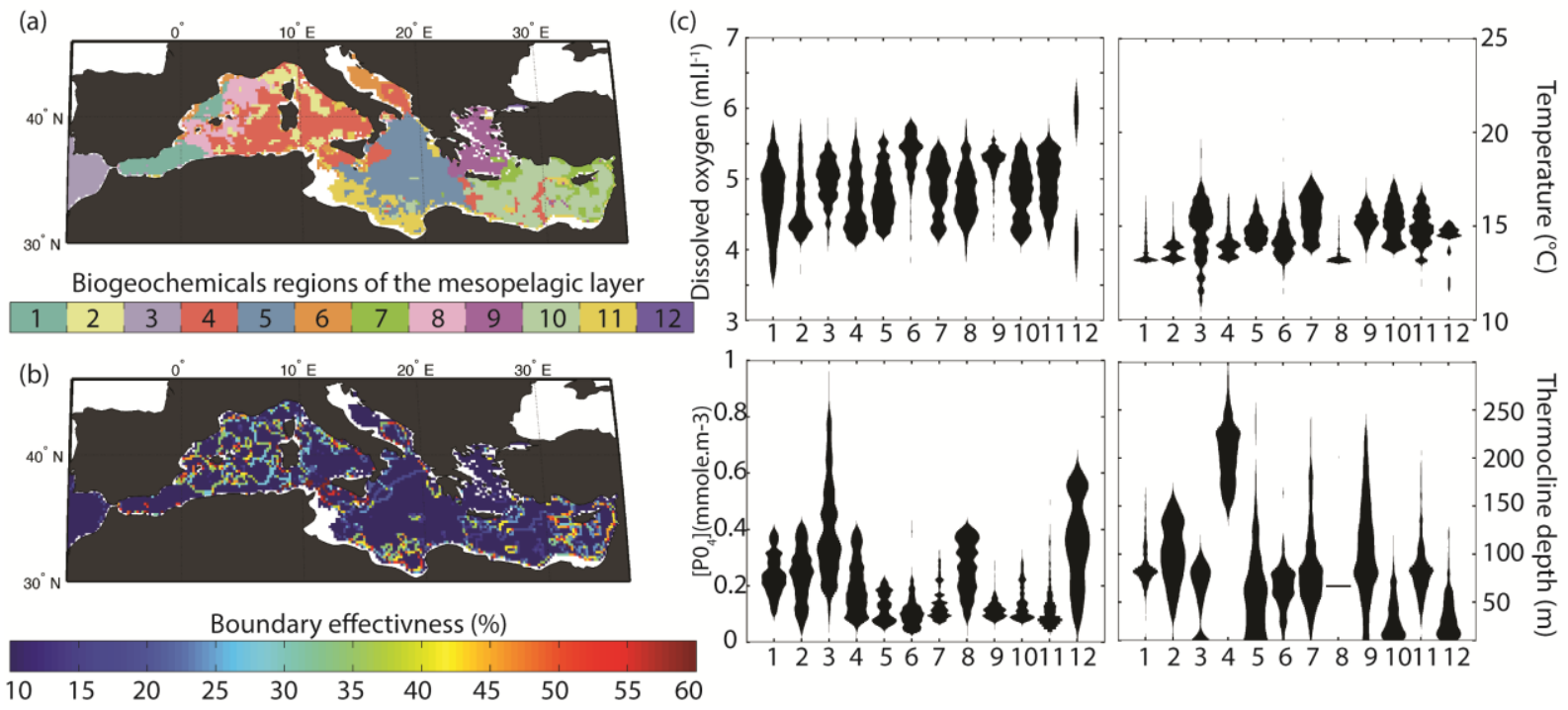

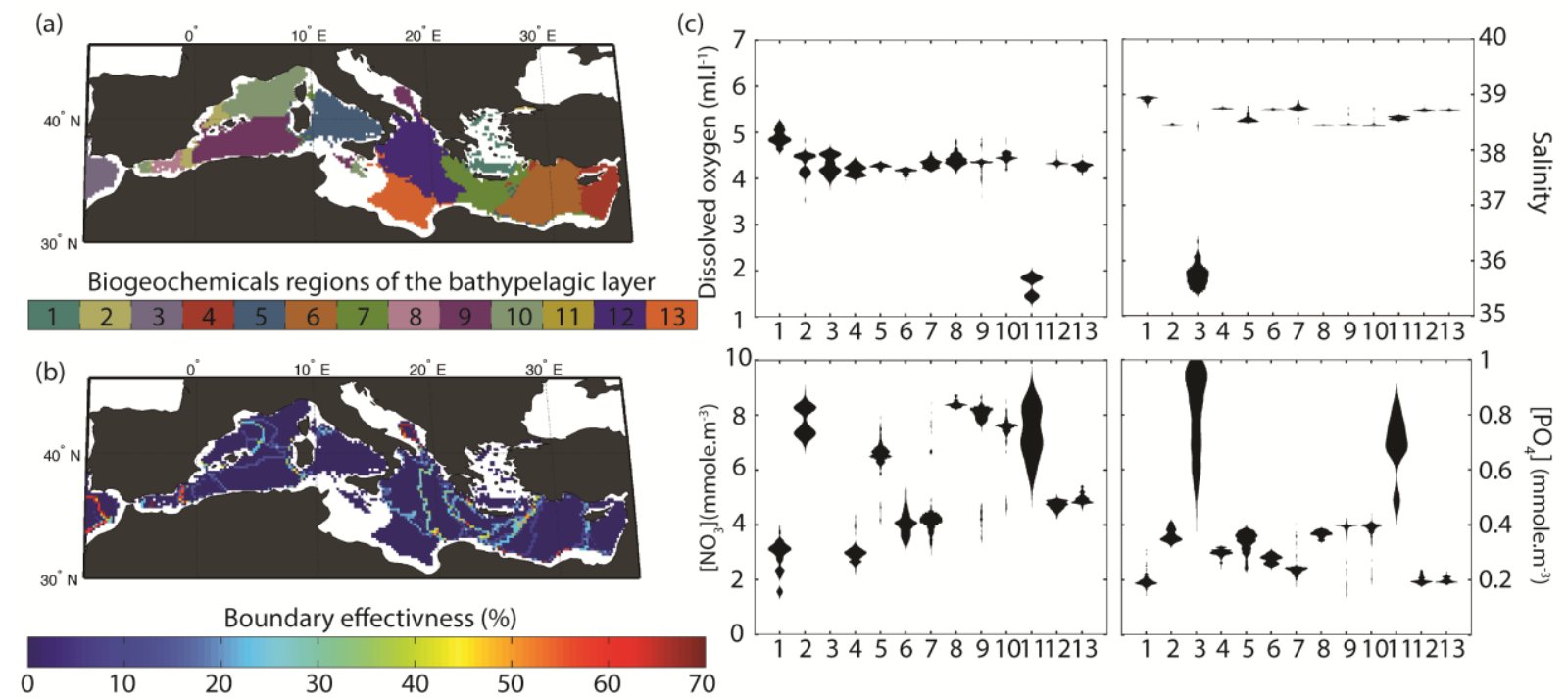

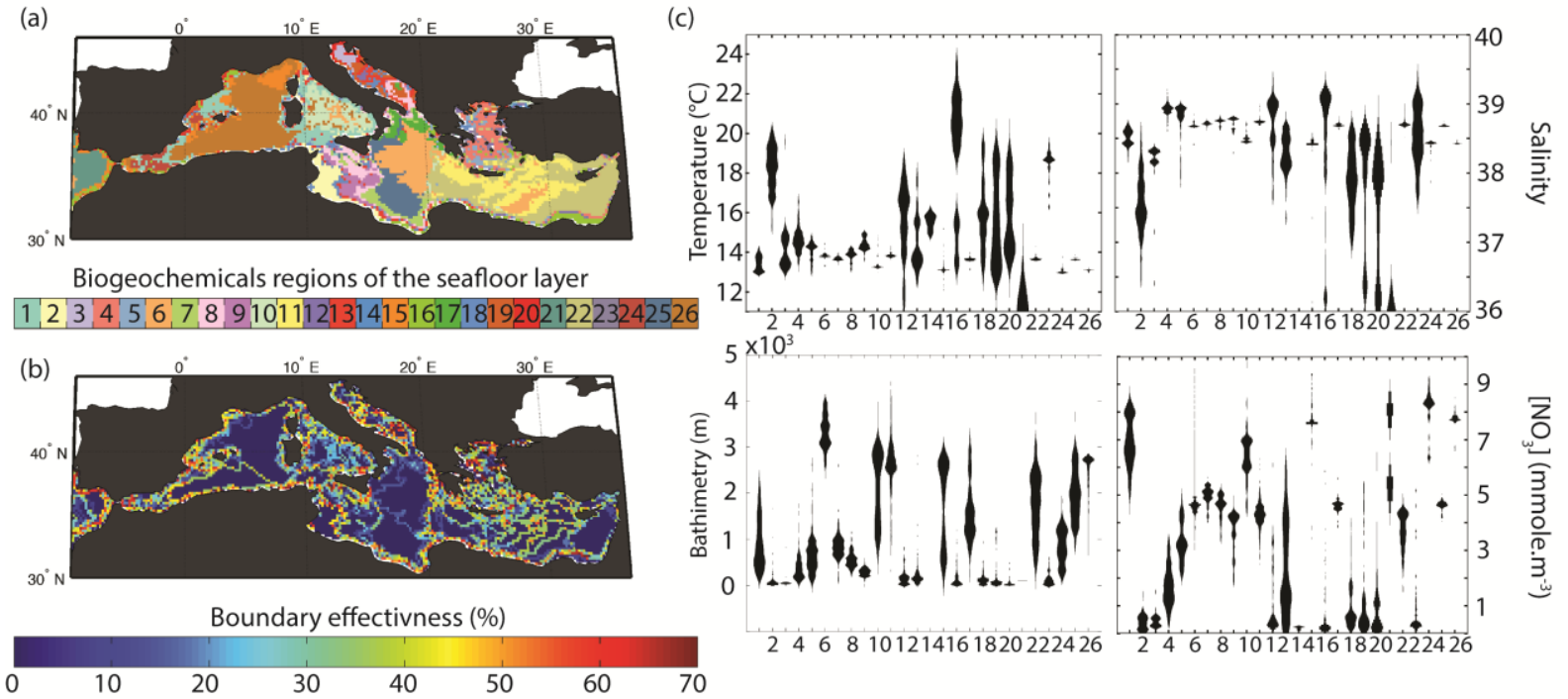


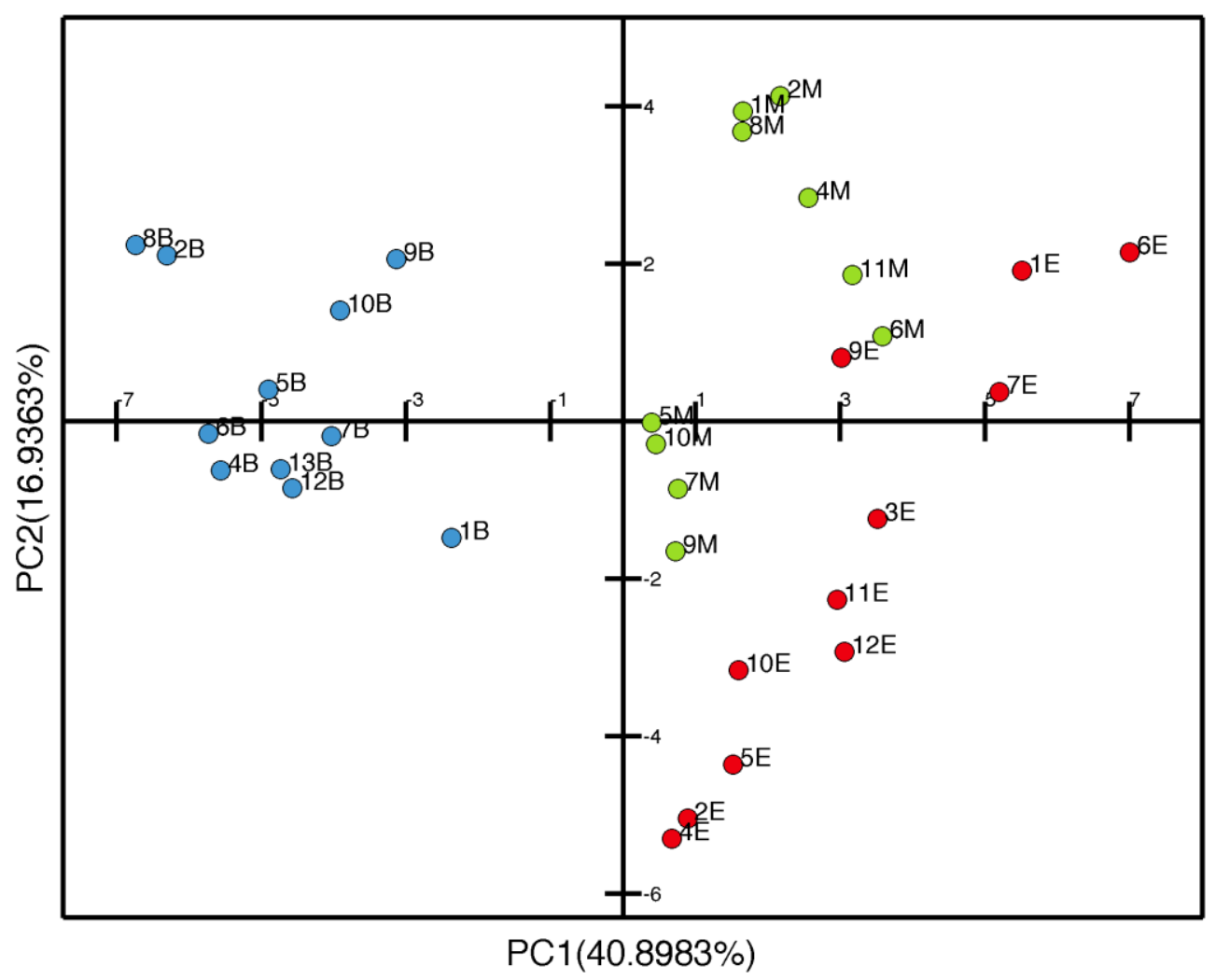


Annexe 1:

\section{Validation of the spatial distribution of the epipelagic BGCRs}

To test the robustness of detected boundaries, the resulting environmental partition was confronted to an independent set of in situ data (collected during an cruise). Owing to the difficulty to retrieve deep environmental sampling originating from the same cruise, and covering both occidental and oriental basins, only the epipelagic layer division (Fig. 1a; main manuscript) could be tested. We here used the surface data collected during the BOUM (Biogeochemistry from the Oligotrophic to the Ultraoligotrophic Mediterranean) cruise (Moutin et al., 2012).

First, the mean value of each parameter gathered along the cruise (Sea Surface Temperature, Sea Surface Salinity, Dissolved oxygen concentration and fluorimetry) was computed for each epipelagic BGCR encountered. Then, a Kruskall Wallis test was performed to test if the mean environmental values were significantly different among BGCR. Second, shift in the values of effectiveness between each BGCR encountered across the cruise were compared to surface parameters gathered along the cruise (Fig. 5 and Fig. 10). An examination of the change in BGCR (marked by an important effectiveness value) was empirically compared to the variation of each nearest parameter values collected during the BOUM campaign (Annexe 1, Fig. 1).

The Kruskall-Wallis test shows significant differences $(p$-value $<0.05)$ over the mean environmental conditions of all the BGCRs crossed during the cruise. Second, the 
comparison revealed that BGCR boundaries (dashed line; Fig.10) coincide with in situ variations of at least one of the parameters sampled. However, changes of the in situ data are also detected within some BGCR.

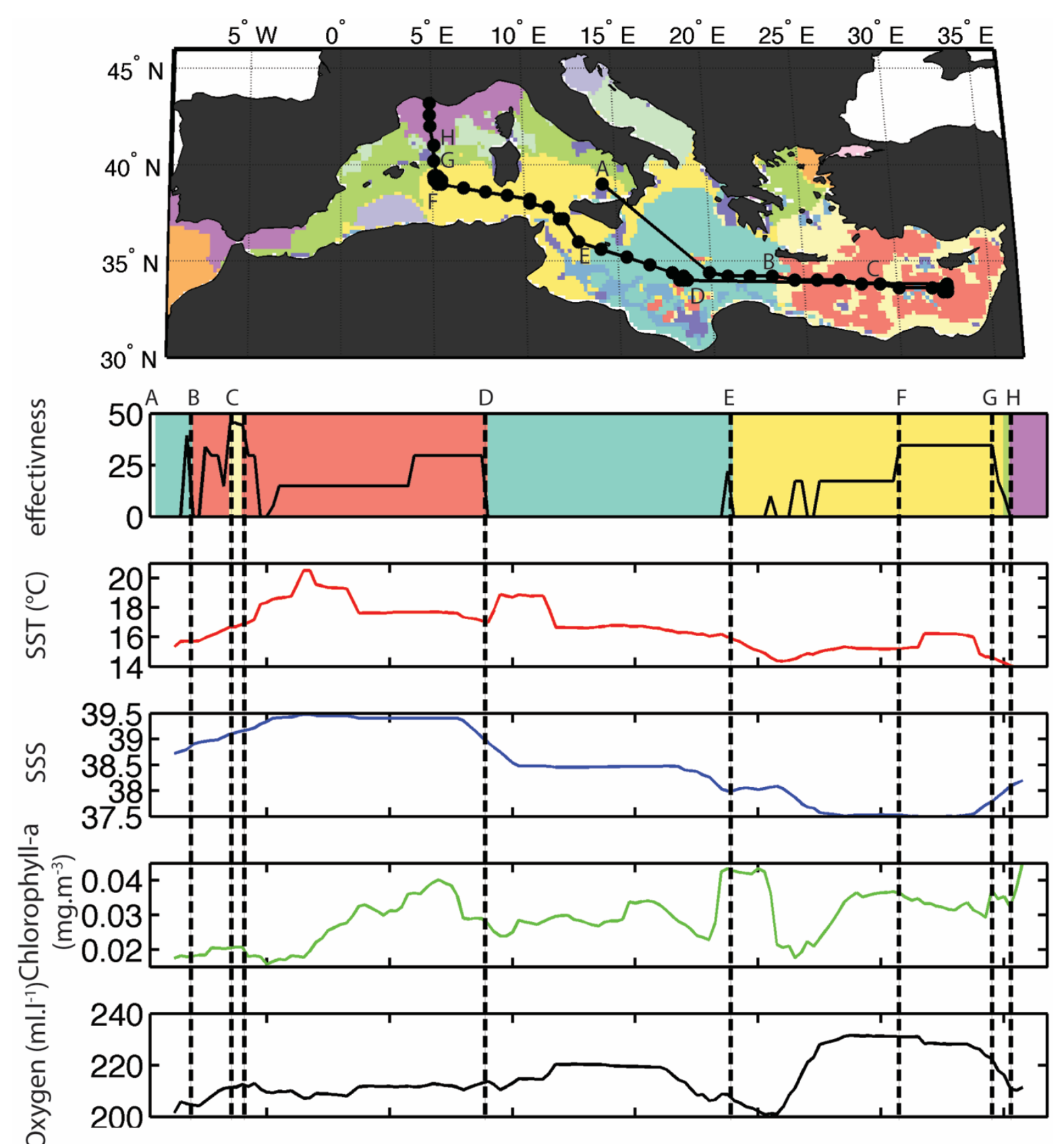

Figure 1 Upper panel: Map of the BOUM cruise superimposed on the map of the epipelagic biogeochemical regions of the MS. Lower panel: Plot of the boundary effectiveness, SST (Sea Surface Temperature), SSS (Sea Surface Salinity), fluorimetry (named here chlorophyll-a) and dissolved oxygen concentration gathered along the cruise. Colours superimposed on the plot of the boundary effectiveness stand for the BGCR crossed. Black vertical dashed lines represent region of changing BGCR. All plots have been smoothed by a running average of 5 . 
Highlights

- This study provides the first 3D atlas of Biogeochemical Regions in the Mediterranean Sea (12 for the epipelagic, 12 for the mesopelagic, 13 for the bathypelagic and 26 for the seafloor)

- The Eastern-Western environmental gradient has a decreasing contribution to the biogeochemical partitions with depth

- The partition of the surface layer cannot not be extrapolated to underneath layers as the partition is driven by different environmental variables

- The study highlights the need of a third level of macro-ecological division at a regional scale to quantify the influence of meso-scale environmental variability that mostly drive semi-enclose seas biogeochemical processes and thus marine habitats. 